\title{
Layer performance, fatty acid profile and the quality of eggs from hens supplemented with Moringa oleifera whole seed meal
}

\author{
S. P. Mabusela ${ }^{1 \#}$, T. T. Nkukwana ${ }^{2}$, M. Mokoma $^{2}$ \& V. Muchenje ${ }^{1}$ \\ ${ }^{1}$ Department of Livestock and Pasture Science, Faculty of Science and Agriculture, University of Fort Hare, \\ Private Bag X1314, Alice, 5700, South Africa \\ ${ }^{2}$ Agricultural Research Council, Animal Production Institute, Private Bag X2, Irene, 0062
}

(Received 5 September 2017; Accepted 29 November 2017; First published online 14 December 2017)

\author{
Copyright resides with the authors in terms of the Creative Commons Attribution 4.0 South African License. \\ See: http://creativecommons.org/licenses/by/4.0/za \\ Condition of use: The user may copy, distribute, transmit and adapt the work, but must recognize the authors and the South African \\ Journal of Animal Science.
}

\begin{abstract}
The objective of the study was to determine how the partial supplementation of Moringa oleifera whole seed meal (MOWSM) would affect layer performance, egg quality and egg fatty acid profile. One hundred and forty-four Hy-Line hens in early-lay (20-weeks-old), with an average body weight of $1.45 \mathrm{~kg}$ were randomly allocated to four dietary treatments which were formulated to meet or exceed the National Research Council standards for brown-egg laying hens. Dietary treatments consisted of 0 (control), 1, 3, and $5 \%$ MOWSM. Layer performance was monitored over a period of 8 weeks. The inclusion of MOWSM in layer diets reduced feed intake, bodyweight, the rate of lay, egg weight, and egg mass. Yolk colour was significantly improved by 1,3 and $5 \%$ inclusion levels, while the albumen height decreased. The albumen weight, yolk weight, eggshell weight, eggshell thickness, and egg shape index showed no statistical differences across all treatment groups. Similarly, the saturated fatty acid profile was also not affected. Palmitoleic acid decreased with the increase in MOWSM inclusion, whilst linolelaidic acid increased. The atherogenicity index was not affected by MOWSM inclusion, while the thrombogenicity index increased when compared to the control diet. It was concluded that, although MOWSM inclusion improved yolk colour, maintained external egg quality, and improved the fatty acid profile, the deleterious effect that it had on layer performance indicated that it may not be fed to early-lay hens at these respective levels.
\end{abstract}

Keywords: Alternative protein, egg production, laying hens, oil seeds

\# Corresponding author: siphomabusela97@gmail.com

\section{Introduction}

Feed accounts for $60-70 \%$ of the total cost in commercial poultry production (Sayda et al., 2011). Soybean meal is the main crude protein (CP) source that is used, as it contains adequately balanced amino acids and satisfactory essential fatty acids (FAs) to satisfy the laying-hen nutritional requirements (Hammershoj \& Steenfeldt, 2005; Shi et al., 2012; de Morais Oliveira et al., 2016). The exceptional performance of soybean meal has increased its demand in the animal feed industry, which has subsequently led not only to its scarcity but also to an increase in its price (Laudadio et al., 2011; Abbas, 2013). In the quest to reduce feeding costs and improve profit margins, the use of non-conventional CP sources to supplement soybean meal in layer diets partially or completely is gaining research and industry interest (Moreki \& Gabanakgosi, 2014). The non-conventional CP source that will be identified to supplement soybean meal in layer diets must also contain adequate FAs that can contribute positively to egg quality and consumer health.

Among other non-conventional CP sources, Moringa oleifera whole seed meal (MOWSM) has been reported to have the potential to be used in monogastric diets (Moreki \& Gabanakgosi, 2014; Ayasan, 2015, Ahmed et al., 2017). There are ten to twelve species of the Moringaceae family that belong to the genus Moringa and M. oleifera is said to be the most commonly used of them all (Abdulkarim et al., 2005; Alikwe \& Omotosho, 2013). The MOWSM contains $95 \%$ dry matter, $3.48 \%$ ash, $39.17 \%$ crude protein, $38.8 \%$ ether extract, and $48 \%$ crude fibre (Mabruk et al., 2010). Although MOWSM contains an exceptional index of nutrients, the presence of anti-nutrient factors (ANF), such as tannins $(2.13 \mathrm{mg} / \mathrm{kg})$, saponins $(2.25 \mathrm{mg} / \mathrm{kg})$, phytate $(41 \mathrm{~g} / \mathrm{kg})$ and high crude fibre $(22.93-38 \%)$, may be a limiting factor in the utilisation of these seeds 
in layer diets (Foidl et al., 2001; Anhwange et al., 2004). Therefore, to limit the impact of ANFs, this trial utilised low levels of MOWSM, in the event that the ANFs would have a negative impact on the parameters evaluated.

To date, there have been several studies done to evaluate the potential of $M$. oleifera leaf meal in broiler chickens (Wapi et al., 2013; Nkukwana et al., 2014). However, there is no documented research that has evaluated the potential of MOWSM in layer diets and the effect it could have on layer performance, egg quality and egg fatty acid profile. Therefore, the aim of the current study was to assess the effect of MOWSM supplementation on layer performance, egg quality, and their fatty acid profile.

\section{Materials and Methods}

The study was conducted at the Agricultural Research Council - Animal Production Institute (ARCAPI) in Irene, Pretoria. The use of animals as well as the experimental design was approved by the Agricultural Research Council Ethics Committee (ARCEC) and the University of Fort Hare Research Ethics Committee (UREC). The following are the certificate reference numbers: ARCEC - (APIEC15/039) and UREC - (NKU061SMAB01), respectively.

A total of $144 \mathrm{Hy}$-Line laying hens at 20 weeks of age, with an average body weight of $1.45 \mathrm{~kg}$ were assigned to four dietary treatments. The treatments contained $M$. oleifera whole seed meal (MOWSM) inclusion levels of $0,1,3$, and $5 \%$. Dietary treatments in Table 2 were formulated to be iso-nitrogenous and iso-energetic to meet and exceed the National Research Council nutrient recommended levels for laying hens (NRC, 1994). The diets were fed at ad libitum to the layers throughout the trial period. Moringa oleifera whole seeds used in the trial were purchased from Moringa South Africa, a company based in Oudtshoorn, South Africa. The seeds were stored for 2 months, grinded through a $1 \mathrm{~mm}$ sieve and transported to the study site where they were mixed with the rest of the trial feed raw materials.

Each treatment group had 36 hens, which were replicated 6 times in a completely randomised design. The stocking density consisted of 2 hens per cage (with an area of $45 \mathrm{~cm} \times 45 \mathrm{~cm}$ ) and three cages were treated as a replicate ( $n=6$ hens/replicate). Each cage was equipped with 1 nipple drinker and a feeding trough; a day-length of 14 hours was used as the source of sunlight.

Proximate analysis was carried out on all experimental diets and on MOWSM for gross energy, CP, crude fibre, moisture, ether extract, ash, as well as calcium and phosphorus using the standard methods of analysis described by the Association of Official Analytical Chemists and the results are shown in Tables 1 and 2 (AOAC, 1991). Both acid detergent fibre (ADF) and neutral detergent fibre (NDF) were determined using a method described by Van Soest et al. (1991). The analysis of the feed was carried out at the ARCAPI Analytical Laboratory in Irene, Pretoria.

Table 1 Chemical and nutrient composition of Moringa oleifera whole seed meal on a dry matter (DM) basis

\begin{tabular}{lc}
\hline Nutrient & Composition (g/kg) \\
\hline Dry matter & 954.0 \\
Moisture & 46.0 \\
Gross energy (MJ/kg) & 234.3 \\
Protein (N x 6.25) & 273.0 \\
Ash & 50.4 \\
Acid detergent fibre, ADF & 305.4 \\
Neutral detergent fibre, NDF & 323.7 \\
Fat (ether extraction) & 229.7 \\
Carbohydrates (Calculated) & 400.9 \\
Crude fibre & 229.3 \\
Analysed mineral composition & 2.8 \\
Calcium & 5.3 \\
Phosphorus & 2 \\
\hline
\end{tabular}

N-nitrogen; MJ -megajoules; kg-kilogram 
Layer performance and egg quality were monitored weekly over the eight-week trial period. Feed intake (FI), bodyweight (BW), the rate of lay (ROL), egg weight (EW) and egg mass (EM) were measured as layer performance parameters. Whilst albumen height (AH), albumen weight (AW), yolk weight (YW), yolk colour (YC), eggshell weight (ESW), eggshell thickness (EST) and egg shape index (ESI) were measured as the parameters to assess egg quality.

Feed intake was determined weekly, while body weights were recorded at the start and at the end of the experiment period. The eggs were collected three times a day and egg weights were taken thereafter. The rate of lay (ROL) was calculated per week by taking the total number of eggs produced and dividing them by the number of hens per treatment group and multiplied by 100. Egg mass (EM) was calculated by multiplying the egg weight (EW) by the ROL per treatment. The data for layer performance was collected and calculated using the procedure and formulas described by Laudadio et al. (2011).

Table 2 Composition of layer diets containing graded level of Moringa oleifera whole seed meal (as fed basis)

\begin{tabular}{|c|c|c|c|c|}
\hline \multirow{2}{*}{ Ingredients } & \multicolumn{4}{|c|}{ Experimental diets } \\
\hline & 0\% MOWSM & 1\% MOWSM & $3 \%$ MOWSM & $5 \%$ MOWSM \\
\hline Yellow Maize & 59.81 & 59.58 & 59.13 & 58.68 \\
\hline Gluten $20 \%$ & 8.07 & 7.22 & 5.53 & 3.83 \\
\hline $\begin{array}{l}\text { Moringa oleifera whole seed } \\
\text { meal }\end{array}$ & 0.00 & 1.00 & 3.00 & 5.00 \\
\hline Soya oilcake & 9.05 & 9.15 & 9.33 & 9.51 \\
\hline Sunflower oilcake & 12.50 & 12.50 & 12.50 & 12.50 \\
\hline Sunflower oil & 0.24 & 0.23 & 0.22 & 0.20 \\
\hline Limestone Powder & 3.71 & 3.71 & 3.72 & 3.73 \\
\hline Limestone Grit & 5.50 & 5.50 & 5.50 & 5.50 \\
\hline Monocalcium Phosphate & 0.43 & 0.42 & 0.40 & 0.37 \\
\hline Salt Fine & 0.21 & 0.21 & 0.21 & 0.21 \\
\hline Methionine Powder & 0.06 & 0.06 & 0.06 & 0.06 \\
\hline Lysine & 0.16 & 0.16 & 0.15 & 0.14 \\
\hline Choline Chloride & 0.06 & 0.06 & 0.06 & 0.06 \\
\hline Layer vitamin \& mineral premix* & 0.20 & 0.20 & 0.20 & 0.20 \\
\hline \multicolumn{5}{|c|}{ Analysed chemical and nutrient composition (DM basis) } \\
\hline Dry matter (\%) & 91.42 & 91.76 & 90.77 & 91.00 \\
\hline Gross energy (MJ/kg) & 15.12 & 15.06 & 15.83 & 15.47 \\
\hline Crude protein \% & 14.85 & 13.60 & 13.39 & 13.93 \\
\hline Lipids & 2.66 & 2.57 & 3.27 & 3.69 \\
\hline $\operatorname{ADF}^{\star *}(\%)$ & 6.06 & 7.48 & 6.30 & 7.28 \\
\hline $\operatorname{NDF}^{\star \star *}(\%)$ & 13.31 & 14.21 & 14.97 & 16.61 \\
\hline Calcium (\%) & 3.32 & 3.24 & 2.14 & 2.57 \\
\hline Phosphorus (\%) & 0.41 & 0.32 & 0.27 & 0.28 \\
\hline Ash (\%) & 12.66 & 11.82 & 7.85 & 10.11 \\
\hline
\end{tabular}

T - Treatment. 0\% MOWSM, control = 0\%; T2 = 1\%; T3 = 3\%; and T4 = 5\% Moringa oleifera Whole Seed Meal Inclusion levels, \% = percentage

*Premix provided per kilogram of diet: vitamin A (1000 000IU), $10000 \mathrm{IU}$; vitamin D3 (500 000IU), $3000 \mathrm{IU}$; vitamin E (500IU), $15 \mathrm{IU}$; vitamin K3 (43\%), $1500 \mathrm{mg}$; vitamin B1, 2000mg; riboflavin (80\%), 4000 mg; Calcium pantothenate, $7000 \mathrm{mg}$; niacin (99.5\%), 28 000mg; vitamin B12, 20mg; vitamin B6 (98\%), 2.50g ;choline (Chloride 60\%), 259.74g; Folic Acid, 0.50g; biotin (2\%), 25mg; Manganese, $70000 \mathrm{mg}$; zinc, $30000 \mathrm{mg}$; copper, $6000 \mathrm{mg}$; iodine, $1000 \mathrm{mg}$; Cobalt, $500 \mathrm{mg}$; iron, 30 000mg; selenium (Sodium selenite 4.5\%), 150mg; (Carrier) Dolomite, $1509701 \mathrm{mg}$

${ }^{* *}$ Acid detergent fibre

${ }^{* * *}$ Neutral detergent fibre 
A total of 72 eggs collected from all treatment groups ( $n=18$ eggs/treatment) were assessed for $\mathrm{AH}$, AW, YW, YC, ESI, EW EST and ESW. The ESI was assessed using an Electronic Digital Calliper (Time Technology, Netherlands) by measuring the width $(\mathrm{mm})$ and height $(\mathrm{mm})$ of the eggs. Egg weight was measured by placing the egg on a HM- 200 scale (A \& D Co., Ltd Japan). Thereafter, the egg was cracked onto a flat surface, where the Electronic Digital Calliper was used to measure the height of the albumen. The YC was assessed using the DSM Colour Yolk Fan (DSM Nutritional Products, Switzerland). The yolk and the albumen were separated with a Pekebo egg yolk-white separator and weighed individually using a digital balance scale (The Lab Depot, Inc.). Following the internal egg quality analysis, the eggshells were washed with distilled water and dried at room temperature over 3 consecutive days. Thereafter, the ESW was measured using a digital balance scale (The Lab Depot, Inc.). The EST was assessed by measuring the thickness of the pointy, equator and blunt end of the egg using the Electronic Digital Calliper (Time Technology, Netherlands). The formulas below were used, respectively, to calculate EST and ESI (Stadelman, 2002; Monira et al., 2003; Parmer et al., 2006).

$\mathrm{EST}=($ pointed end + equator + blunt end $) / 3$

$\mathrm{ESI}=($ egg width $/$ egg length $) \times 100$

For the determination of the fatty acid profile, 18 eggs ( $n=3$ eggs/ replication) were collected on the last day of the trial, for the analysis of FAs using the Gas Liquid Chromatography (GLC) method as described by Christopherson and Glass (1969). Fatty acid methyl esters (FAME) were prepared by transesterification as described by (Garces \& Mancha, 1993). One $\mu$ l sample of the FAME was injected into the GLC and the resolution of the individual fatty acid was recorded. The unknown fatty acids were identified by comparing them to a known standard of FAs injected under the same temperature and pressure. The Shimadzu CR4-A Chromatopac was used to determine the percentage of each FA in the FAME. The atherogenicity index (Al) and thrombogenicity index were calculated using the formulas below.

$\left.\mathrm{Al}=\left[\left(4^{*} \mathrm{C} 14: 0\right)+\mathrm{C} 16: 0+\mathrm{C} 18: 0\right] \div \Sigma \mathrm{MUFA}+\Sigma \mathrm{PUFA}-\mathrm{n6}+\sum \mathrm{PUFA}-\mathrm{n3}\right]$

(Senso et al., 2007; Garaffo et al., 2011)

$\mathrm{TI}=[\mathrm{C} 14: 0+\mathrm{C} 16: 0+\mathrm{C} 18: 0] \div\left[0.5^{*} \Sigma \mathrm{MUFA}+0.5^{\star} \Sigma \mathrm{PUFA}-\mathrm{n6}+3^{*} \Sigma \mathrm{PUFA}-\mathrm{n} 3 / \Sigma \mathrm{PUFA}-\mathrm{n6}\right]$

(Senso et al., 2007; Garaffo et al., 2011)

The data was statistically analysed using a completely randomised One-way analysis of variance (ANOVA). The variables that were measured include the ROL, FI, BW, EM, AH, AW, YW, YC, ESI, EW, EST, ESW, FAs, Al, and TI. The general linear model procedure (PROC- GLM) of the SAS program (SAS, 2004) was used to test for significant $(P<0.05)$ differences between the treatment means, whilst Tukey's significant difference test was used for mean separation. The statistical linear model used was

$$
Y=\mu+T_{i}+e
$$

Where: $Y=$ variables studied over the 8-week period,

$\mu=$ overall mean of the population,

$\mathrm{T}_{\mathrm{i}}=$ effect associated with the ith level of MOSWM, and

$\mathrm{e}=$ random error associated with the variables tested.

\section{Results and Discussion}

The effect of MOWSM dietary inclusion on feed intake (FI), bodyweight (BW), the rate of lay (ROL), egg weight (EW) and egg mass (EM) is presented in Table 3. The dietary inclusion of MOWSM had a decreasing effect $(P<0.05)$ on $\mathrm{Fl}$. The $\mathrm{FI}$ of birds fed on $5 \%$ of the MOWSM diet was the lowest $(P<0.05)$, while those fed diets with less or no MOWSM had the highest. A similar trend was observed with the change in BW. Birds that were fed $5 \%$ of the MOWSM had the lowest gains $(P<0.05)$ or were unable to maintain their BW, compared to those fed on the control diet. Hassan et al. (2017) observed similar results, reporting that $\mathrm{FI}$ and BW decreased with the increase of MOWSM in broiler diets. These results are also in line with those observed by Talha \& Ahmed (2012) who concluded that an increase in MOWSM led to a depression in $\mathrm{FI}$ and BW of laying hens. Sayda et al. (2011) reported concurring results, where high inclusion levels of sunflower seed meal (SSM) in layer diets were observed to decrease FI. In a study conducted by Ahmed and Abdelati (2009), it was also observed that the inclusion of Leucaena leucaephala seed (LLS) in layer diets had a negative effect on FI. All the above results show that some unconventional feed ingredients depreciate $\mathrm{FI}$, which ultimately leads to a decrease in the BW of layers. 
Anti-nutritive factors (ANF) such as phytate, saponins, tannins, oxalates, trypsin inhibitors and cyanogenic glycoside play a monumental role in the digestibility-potential of vegetable feed ingredients (Soetan \& Oyewole, 2009). Moringa oleifera whole seed meal is higher in phytate content $(10.18 \mathrm{mg} / 100 \mathrm{~g}$ ) when compared to other vegetable feed ingredients (Foidl et al., 2001; Anhwange et al., 2004). The seeds also contain other ANFs such as tannins $(2.13 \mathrm{mg} / \mathrm{kg})$ and saponins $(2.25 \mathrm{mg} / \mathrm{kg})$ that may have a deleterious effect on animal performance (Anhwange et al., 2004). The decrease in FI could have been attributed to the presence of phytate, tannins and saponins, which all can suppress $\mathrm{FI}$ due to their unpalatable and nutrient-binding nature (Anhwange et al., 2004). Hassan et al. (2017) concurred with these results and attributed the decrease in FI and BW to the phytate available in the MOWSM which reduces bioavailability of minerals and the digestibility of starch and protein. Ahmed et al. (2017) also reported that the decrease in production performance of layer chickens fed with $M$. oleifera pod meal was a result of the high fibre and ANFs which resulted in a bulky diet that decreased nutrient digestibility in the gut.

Table 3 Mean $( \pm S E)$ layer performance and egg production from hens fed on different inclusion levels of Moringa oleifera Whole Seed Meal

\begin{tabular}{lccccc}
\hline \multirow{2}{*}{ Layer performance } & \multicolumn{4}{c}{ Moringa oleifera Whole Seed Meal Inclusion levels } & \multirow{2}{*}{$\boldsymbol{P}$-value } \\
\cline { 2 - 5 } & $\mathbf{0 \%}$ - Control & $\mathbf{1 \%}$ & $\mathbf{3} \%$ & $\mathbf{5 \%}$ & \\
\hline & & & & & \\
Feed intake $(\mathrm{g} / \mathrm{kg})$ & $115.97^{\mathrm{a}} \pm 0.01$ & $91.78^{\mathrm{b}} \pm 0.01$ & $89.43^{\mathrm{b}} \pm 0.02$ & $80.24^{\mathrm{b}} \pm 0.02$ & $<.0001$ \\
Body weight $(\mathrm{kg})$ & $1.45^{\mathrm{a}} \pm 2.74$ & $1.39^{\mathrm{b}} \pm 3.10$ & $1.36^{\mathrm{b}} \pm 3.38$ & $1.31^{\mathrm{c}} \pm 3.56$ & $<.0001$ \\
Rate of Lay (\%) & $72.65^{\mathrm{a}} \pm 2.07$ & $59.60^{\mathrm{b}} \pm 2.50$ & $49.56^{\mathrm{c}} \pm 2.64$ & $48.21^{\mathrm{c}} \pm 2.78$ & $<.0001$ \\
Egg weight (g) & $62.89 \pm 0.54$ & $61.93 \pm 0.82$ & $63.15 \pm 0.85$ & $60.70 \pm 0.76$ & 0.0900 \\
Egg mass (\%) & $60.23^{\mathrm{a}} \pm 2.98$ & $47.43^{\mathrm{b}} \pm 3.51$ & $36.01^{\mathrm{c}} \pm 3.24$ & $33.45^{\mathrm{c}} \pm 2.87$ & $<.0001$
\end{tabular}

$\overline{a, b, c}$ Values with different letters within a row differ significantly at $(P<0.05) ; \mathrm{g} / \mathrm{kg}=\mathrm{gram}$ per kilogram; $\mathrm{kg}=\mathrm{kilogram;} \mathrm{g}=$ gram; \% = percentage

Studies conducted by Ahmed and Abdelati (2009) and Sayda et al. (2011) observed that the dietary inclusion of seed meals such as SSM and LLS had a decreasing effect on BW. The decrease in BW in the current study could have been attributed to the low FI, which may have been induced by the ANFs in MOWSM. Besides their unpalatability, saponins and phytate also bind to the exogenous and endogenous protein, cations, and enzymes; thus, decreasing the uptake and metabolism of proteins and other essential nutrients in the gut of the hen (Anhwange et al., 2004). The unavailability of essential nutrients from the gastro intestinal tract force layer hens to utilise body reserves to sustain their nutrient needs, subsequently leading to decreased BWs. Moringa oleifera whole seeds contain $0.58 \mathrm{mg} / 100 \mathrm{~g}$ of hydrogen cyanide, which is also one of the ANFs (Anhwange et al., 2004). Hydrogen cyanide has been reported to have a significant decreasing effect on weight change (Alikwe \& Omotosho, 2013). Animals detoxify cyanide through cyanide thiocyanate sulphur-transferase, which require organic sulphur donors in the form of methionine and cysteine amino acids. This subsequently leads to a deficiency of amino acids, which leads to a decrease in animal weight and growth (Akinmutimi \& Okwu, 2006). Contrary to the results found by the above researchers, Ahmed et al. (2017) found Moringa oleifera seed pod meal to have no effect on FI. Similarly, Paguia et al. (2014) found the inclusion of Moringa oleifera leaf meal to have no effect on FI.

The inclusion of MOWSM in the layer diets also had a decreasing effect on the rate of lay (ROL) $(P$ $<0.05)$. The ROL was the lowest in birds that received diets with $5 \%$ of MOWSM $(48.21 \%)$ compared to those of the control diet (72.65\%). Ahmed and Abdelati (2009) reported similar results with the inclusion of LLS in layer diets when they concluded that the ROL decreased with the increase of LLS. The decrease in the ROL could have been attributed to the decrease in the FI and BW, with the limited nutrients that the layers consumed being focused mainly on body maintenance and less on the production of eggs. Saponins and phytic acid present in most seed meals limit the availability of protein in the gut, with hens consequently prioritising maintenance of their body condition as opposed to laying eggs (Anhwange et al., 2004). Results from studies carried out by Tsuzuki et al. (2003) and Shi et al. (2012) observed that SSM supplementation had no effect on the ROL and this may validate the ANF justification since SSM is low in ANFs like phytic acid and saponins. These results are in line with Ahmed et al. (2017) when it was reported that the inclusion of Moringa oleifera pod meal had no effect on the ROL. 
The EW across all dietary treatments with MOWSM was within the same range as those of the control group $(P=0.09)$. Similar results were found by Ahmed et al. (2017) when EW was not affected by the inclusion of Moringa oleifera pod meal in layer hen diets. Concurring results were also found when Ahmed and Abdelati, (2009) and Shi et al. (2012) reported that EW was not affected by the presence of LLS and SSM in the layer diet, respectively. Egg weight is influenced mainly by genetics, environment, and hen age (Albrecht, 2011). This could explain why there was no statistical difference in the current study because all the chickens were of the same age and strain. The supplementation of MOWSM in layer diets had a decreasing effect on EM $(P<0.05)$. Since the calculation of EM includes both EW and ROL, any differences on the two variables are ultimately expressed in the EM. Therefore, the difference in EM between the treatments could be attributed to the differences that were observed in the ROL. Sayad et al. (2011) observed corresponding results, and concluded that SSM inclusion in layer diets influenced EM. However, unlike the current study, Sayad et al. (2011) found SSM in layer diets to improve EM. Similarly,

Data on egg quality is presented in Table 4, showing the effect of MOWSM on AH, AW, YW, YC, ESW, EST, and EST. Albumen height was reduced when MOWSM was included in the layer diet $(P<0.05)$ and this decrease in $\mathrm{AH}$ became more prominent as the inclusion of MOWSM increased. In a study conducted by Shi et al. (2012), it was concluded that a decrease in AH was caused by the presence of ANFs with the included SSM batch in the layer diets. Since there were ANFs in MOWSM then it can thus be concluded that $\mathrm{AH}$ was also decreased by the presence of ANFs.

Table 4 Mean $( \pm$ SE) effects of different inclusion levels of Moringa oleifera Whole Seed Meal on internal and external egg quality attributes

\begin{tabular}{lccccc}
\hline \multirow{2}{*}{ Egg Quality } & \multicolumn{4}{c}{ Moringa oleifera Whole Seed Meal Inclusion levels } & \multirow{2}{*}{$\boldsymbol{P}$-value } \\
\cline { 2 - 5 } & $\mathbf{0 \%}$ - Control & $\mathbf{1} \%$ & $\mathbf{3 \%}$ & $\mathbf{5 \%}$ & \\
\hline Albumen height $(\mathrm{mm})$ & $7.72^{\mathrm{a}} \pm 0.21$ & $7.23^{\mathrm{ab}} \pm 0.18$ & $6.72^{\mathrm{b}} \pm 0.20$ & $6.84^{\mathrm{b}} \pm 0.16$ & 0.0007 \\
Albumen weight $(\mathrm{g})$ & $39.41 \pm 0.54$ & $38.52 \pm 0.71$ & $38.82 \pm 0.89$ & $37.91 \pm 0.57$ & 0.4886 \\
Yolk weight $(\mathrm{g})$ & $14.78 \pm 0.22$ & $15.22 \pm 0.21$ & $15.46 \pm 0.20$ & $15.49 \pm 0.24$ & 0.0798 \\
Yolk Colour & $6.96^{\mathrm{b}} \pm 0.13$ & $7.65^{\mathrm{a}} \pm 0.14$ & $8.07^{\mathrm{a}} \pm 0.14$ & $7.78^{\mathrm{a}} \pm 0.12$ & $<.0001$ \\
Eggshell weight (g) & $8.00 \pm 0.08$ & $7.93 \pm 0.09$ & $7.85 \pm 0.10$ & $7.85 \pm 0.09$ & 0.6047 \\
Eggshell thickness (mm) & $0.41 \pm 0.01$ & $0.43 \pm 0.01$ & $0.41 \pm 0.01$ & $0.43 \pm 0.01$ & 0.0791 \\
Egg shape index (\%) & $78.32 \pm 0.31$ & $79.02 \pm 0.36$ & $78.42 \pm 0.46$ & $80.47 \pm 1.01$ & 0.4700 \\
\hline a,b Values with different letters within a row differ significantly at $(P<0.05) ; \mathrm{mm}=$ millimeter & &
\end{tabular}

Albumen weight and YW however were both not affected by the inclusion of MOWSM $(P>0.05)$ in the layer diet. Similarly, Tasfaye et al. (2014) and Ahmed et al. (2017) reported that an increase in moringa oleifera leaf and pod seed meal in layer diets had no effect on EST and ESI, respectively. Sayda et al. (2011) found contrasting results with the inclusion SSM in layer diets, which was found to increase the YW. Yolk colour was improved $(P<0.05)$ by the inclusion of MOWSM in the layer diet at 1,3 and $5 \%$. The layer diet containing MOWSM had the most effect on YC and this was affected by the carotenoids present in oil seeds like MOWSM. The oil present in the oil seeds does help with pigmentation in the yolk and this could explain why diets supplemented with MOWSM had better yolk colour scores when compared to the control diet (Costa et al., 2008).

A study by Tsuzuki et al. (2003) also found that the inclusion of SSM had a significant effect on YC. Eggshell weight, EST and ESI results showed that the inclusion of MOWSM had no effect when compared to the control group $(P>0.05)$. Concurring results were reported by Novak and Scheidler (2001) and Bean and Leeson (2003) who concluded that flax seed inclusion had no effect on the eggshell quality. Contradicting results were observed by Ahmed and Abdelati (2009), who indicated that the inclusion of LLS to layer diets influenced ESW but not on EST.

The effect of MOWSM on the fatty acid profile eggs is shown in Table 5. The inclusion of MOWSM in this study was observed to have no effect $(P>0.05)$ on the total fat content throughout the treatment groups. Total saturated (SFA), monounsaturated (MUFA) and polyunsaturated (PUFA) fatty acids were all similar $(P$ $>0.05)$ throughout the treatment groups. A similar trend was found on the omega $3(n-3), 6(n-6)$, and $9(n-9)$ fatty acid groups; respectively. All the SFAs detected in the egg yolk were found to be the same $(P>0.05)$ throughout the treatment diets. Palmitic and stearic acid are among the fatty acids which are used in the 
calculation of $\mathrm{AV}$ as an indication of the atherogenic nature of the eggs (Senso et al., 2007; Garaffo et al., 2011). Although there were no significant differences in the current study with regards to palmitic and stearic acid throughout the diets, the increase of MOWSM induced a decrease in the two fatty acids; indicating that the inclusion of more MOWSM in the diet could improve the health potential of the eggs.

It was found that even though oleic acid is the dominant MUFA in MOWSM, palmitoleic acid was the only MUFA to be affected $(P<0.05)$ by the inclusion of MOWSM in layer diets. It may be possible that the levels of oleic acid present in the diet were not sufficient to induce a significant effect throughout the diets.

Table 5 Mean $( \pm$ SE) effects of different levels of Moringa oleifera whole seed meal on fatty acid profile of eggs

\begin{tabular}{|c|c|c|c|c|c|}
\hline \multirow{2}{*}{ Fatty Acid } & \multicolumn{4}{|c|}{ Moringa oleifera Whole Seed Meal inclusion levels } & \multirow{2}{*}{$P$-value } \\
\hline & $0 \%$ - Control & $1 \%$ & $3 \%$ & $5 \%$ & \\
\hline Total Fat Content & $25.46 \pm 0.313$ & $25.56 \pm 0.355$ & $24.96 \pm 0.338$ & $25.35 \pm 0.431$ & 0.688 \\
\hline C12:0 & $0.01 \pm 0.000$ & $0.01 \pm 0.000$ & $0.01 \pm 000$ & $0.17 \pm 0.166$ & 0.414 \\
\hline C14:0 & $0.10 \pm 0.000$ & $0.09 \pm 0.000$ & $0.10 \pm 0.004$ & $0.09 \pm 0.000$ & 0.798 \\
\hline C16:0 & $6.70 \pm 0.054$ & $6.56 \pm 0.157$ & $6.57 \pm 0.197$ & $6.35 \pm 0.134$ & 0.424 \\
\hline C18:0 & $1.64 \pm 0.076$ & $1.64 \pm 0.082$ & $1.51 \pm 0.055$ & $1.35 \pm 0.275$ & 0.512 \\
\hline C21:0 & $0.01 \pm 0.002$ & $0.02 \pm 0.004$ & $0.02 \pm 0.002$ & $0.01 \pm 0.003$ & 0.069 \\
\hline C22:0 & $0.05 \pm 0.015$ & $0.04 \pm 0.012$ & $0.02 \pm 0.004$ & $0.01 \pm 0.006$ & 0.051 \\
\hline C23:0 & Not detected & $0.84 \pm 0.833$ & $0.04 \pm 0.000$ & $0.01 \pm 0.002$ & 0.414 \\
\hline$\Sigma S F A$ & $8.38 \pm 0.131$ & $8.23 \pm 0.196$ & $8.29 \pm 0.250$ & $7.90 \pm 0.306$ & 0.499 \\
\hline C16:1n7 & $1.27^{a} \pm 0.054$ & $1.22^{a b} \pm 0.039$ & $1.15^{\mathrm{ab}} \pm 0.054$ & $1.02^{b} \pm 0.084$ & 0.041 \\
\hline C17:1 & $0.04 \pm 0.000$ & $0.04 \pm 0.001$ & $0.04 \pm 0.001$ & $0.04 \pm 0.002$ & 0.098 \\
\hline C18:1n9c & $12.24 \pm 0.203$ & $12.53 \pm 0.215$ & $12.91 \pm 0.412$ & $12.79 \pm 0.235$ & 0.357 \\
\hline C18:1n9t & $0.03 \pm 0.012$ & $0.03 \pm 0.010$ & $0.03 \pm 0.011$ & $0.24 \pm 0.212$ & 0.418 \\
\hline C20:1 & $0.08 \pm 0.003$ & $0.08 \pm 0.004$ & $0.07 \pm 0.011$ & $0.08 \pm 0.004$ & 0.686 \\
\hline C24:1 & $0.05 \pm 0.003$ & $0.04 \pm 0.002$ & $0.05 \pm 0.002$ & $0.05 \pm 0.022$ & 0.347 \\
\hline$\Sigma$ MUFA & $13.61 \pm 0.223$ & $13.93 \pm 0.229$ & $14.25 \pm 0.456$ & $13.99 \pm 0.303$ & 0.568 \\
\hline C18:2n6c & $2.82 \pm 0.116$ & $2.67 \pm 0.151$ & $2.52 \pm 0.086$ & $2.74 \pm 0.111$ & 0.361 \\
\hline C18:2n6t & $0.01^{b} \pm 0.000$ & $0.01^{b} \pm 0.000$ & $0.01^{b} \pm 0.000$ & $0.03^{a} \pm 0.008$ & 0.001 \\
\hline C20:2 & $0.04 \pm 0.006$ & $0.03 \pm 0.004$ & $0.03 \pm 0.003$ & $0.04 \pm 0.004$ & 0.050 \\
\hline C20:4n6 & $0.24 \pm 0.009$ & $0.24 \pm 0.009$ & $0.24 \pm 0.009$ & $0.26 \pm 0.011$ & 0.512 \\
\hline$\Sigma$ PUFA & $3.19 \pm 0.071$ & $3.05 \pm 0.105$ & $3.05 \pm 0.093$ & $3.11 \pm 0.119$ & 0.163 \\
\hline Cis fats & $15.14 \pm 0.316$ & $15.27 \pm 0.264$ & $15.43 \pm 0.461$ & $15.60 \pm 0.265$ & 0.793 \\
\hline Trans fats & $0.03 \pm 0.012$ & $0.04 \pm 0.010$ & $0.04 \pm 0.011$ & $0.27 \pm 0.212$ & 0.332 \\
\hline Omega-3 & $0.04 \pm 0.015$ & $0.01 \pm 0.003$ & $0.02 \pm 0.009$ & $0.05 \pm 0.014$ & 0.103 \\
\hline Omega-6 & $3.05 \pm 0.119$ & $3.05 \pm 0.103$ & $2.84 \pm 0.094$ & $3.09 \pm 0.103$ & 0.344 \\
\hline Omega-9 & $12.27 \pm 0.204$ & $12.56 \pm 0.217$ & $12.94 \pm 0.419$ & $13.03 \pm 0.325$ & 0.285 \\
\hline Atherogenic Index & $0.56 \pm 0.061$ & $0.50 \pm 0.009$ & $0.49 \pm 0.008$ & $0.48 \pm 0.002$ & 0.379 \\
\hline Thrombogenic Index & $0.45^{b} \pm 0.090$ & $0.63^{\mathrm{ab}} \pm 0.021$ & $0.66^{a} \pm 0.012$ & $0.54^{\mathrm{ab}} \pm 0.051$ & 0.041 \\
\hline
\end{tabular}

\footnotetext{
${ }^{a, b}$ Values in the same row with different letters are significantly different

$c$ - cis

MUFA - Monounsaturated fatty acid

PUFA - Polyunsaturated fatty acid

SFA - Saturated fatty acid

$t$ - trans
} 
The trend shows that an increase in MOWSM inclusion brings about a decrease in the palmitoleic acid in the egg yolk. In the PUFAs, linolelaidic acid was the only FA to be affected $(P<0.05)$ by the inclusion of MOWSM. As the inclusion of MOWSM increased, so did the percentage of linolelaidic acid content in the egg yolk. This could be an indication that if the concentration of MOWSM would increase in the diet, then the concentration of linolelaidic acid would also increase significantly. Laying hens can convert linolenic acid to its n-3 products; eisopentsenoic acid and docosahexaenoic by desaturation and elongation in the liver, and these elongated metabolites are deposited in the egg yolk (Collins et al., 1997; Ayerza \& Coates, 2000).

The Al in the egg yolks was found to be unaffected $(P>0.05)$ by the inclusion of MOWSM in the diet. Anti-atherogenic lipids inhibit the aggregation of plaque and diminishing the levels of esterified FA, cholesterol, and phospholipids, thereby preventing the appearance of micro and macro-coronary diseases (Tsiplakou et al., 2008). The increase of MOWSM in the respective treatment groups produced a decrease in the Al value but the decrease was not significant. As it was observed in the fatty acid profile, this decrease may imply that an increase in MOWSM in the diets would have a possible health benefit to the consumers. This response correlates to the palmitic and stearic acid that were not significantly different, but still exhibited a mathematical decreasing trend with the increase in MOWSM content.

The results also indicate that MOWSM had a significant effect on TI values. According to Garaffo et al. (2011), the TI has the tendency to form clots in the blood vessels and it is defined as the relationship between the pro-thrombogenetic FA, which are the SFAs and anti-thrombogenetic FAs, as in the MUFAs, PUFAs, -n6 and -n3; respectively.

\section{Conclusions}

From the results obtained from this trial, it can be concluded that supplementation of MOWSM in layer diets decreased layer performance, with the exception of EW. With regards to egg quality, AH decreased with the increase in MOWSM dietary inclusion but YW, ESW, EST, and ESI were not affected. Yolk colour, on the other hand, had a directly proportional relationship with the inclusion of MOWSM. Except for palmitoleic and linolelaidic acids, eggs across all treatments showed a similar enrichment with FAs. The health indices yielded variable results. The dietary inclusion of MOWSM at 3 and $1 \%$ MOWSM has a greater potential to harm consumer health, when compared to 0 and 5\% MOWSM that had the lowest IT values, respectively. More research may still need to go into determining why the inclusion of MOWSM produces variable $\mathrm{TI}$ values at these inclusion levels. It may be concluded that although partial supplementation of MOWSM at levels ranging from 1 to $5 \%$ may maintain external egg quality, improve YC and some FA enrichment but the deleterious effects it has on layer performance, and $\mathrm{AH}$, it may not be used at these levels in early-lay diets.

\section{Acknowledgements}

The authors would like to thank the National Research Foundation (NRF) and the Govan Mbeki Research and Development Centre (GMRDC) for assisting with funding which made this study possible. The authors are also grateful to the Agricultural Research Council - Animal Production Institute and DSM Nutritional Products, South Africa for providing experimental facilities as well as for sponsoring the study with research equipment.

\section{Authors' Contributions}

SPM, TTN, MM and VM oversaw the experimental design, implementation and writing the manuscript. All authors participated in interpreting and reviewing the results of the study.

\section{Conflict of Interest Declaration}

There are no conflicts of interest.

\section{References}

Abbas, T., E., 2013. The use of Moringa oleifera in poultry diets. Turk. J. Vet. Anim. Sci. 37: 492-496.

Abdulkarim, S.M., Long, K., Lai, O.M., Muhammad, S.K.S \& Ghazali, H.M., 2005. Some physicochemical properties of Moringa oleifera seed oil extracted using solvent and aqueous enzymatic methods. Food Chem. 93, 253-263.

Ahmed, M.E., \& Abdelati, K.A., 2009. Effect of dietary graded levels of Leucaena leucocephala seeds on layers performance, egg quality and blood parameters. Int. J. Poult. Sci. 5, 475-479.

Akinmutimi, A.H. \& N.D. Okwu., 2006. Effect of quantitative substitution of cooked Mucuna utilis seed meal for Soybean meal in broiler finisher diet. Int. J. Poult. Sci. 5, 477-481. 
Albrecht, H.N., 2011. Reproductive soundness of egg quality in chickens selected for low and high antibody response. MSc (Animal Poultry Science) thesis. Virginia Polytechnic Institute and State University. The United States of America.

Alikwe, P.C.N, \& Omotosho, M.S., 2013. An evaluation of the proximate and phytochemical composition of moringa oleifera leaf meal as potential feedstuff for non-ruminant livestock. Agrosh. 13, 17-27

Anhwange, B. A., Ajibola, V.O. \& Oniye, S.J., 2004. Amino acid composition of the seeds of Moringa oleifera (Lam), Detarium microcarpum (Guill \& Sperr) and Bauhinia monandra (Linn.). J. Biol. Sci, 9-13.

Association of Official Analytical Chemists (AOAC)., 1991. Official method of analysis (15th Ed). Association of Official Analytical Chemists. Arlington, VA.

Ahmed, S., Khalique, A., Pasha, T.N., Mehmood, S., Hussain, K., Ahmad, S., Shaheen, M.S., Naeem, M \& Shafiq, M., 2017. Effect of Moringa oleifera (Lam.) pods as feed additive on egg antioxidants, chemical composition and performance of commercial layers. S. Afr. J. Anim Sci. 47, 864-874.

Ayerza, R., \& Coates, W., 2001. Omega-3 enriched eggs: The Influence of dietary a-linolenic acid fatty acid source on egg production and composition. Can. J. Anim. Sci.81, 355-362.

Ayaşan T., 2015. Use of moringa oleifera in poultry and ruminant nutrition. Turkish JAF Sci.Tech.6,425-429.

Bean, L.D. \& Leeson, S., 2003. Long-term effects of feeding flaxseed on performance and egg fatty acid composition of brown and white hens. Poult Sci. 82, 388-394.

Christopherson, S.W. \& Glass, R.L., 1969. Preparation of milk fat methyl esters by alcoholysis in an essentially non-alcoholic solution. J. Dairy Sci. 52, 1289-1290.

Collins, V.P., Cantor, A.H., Pescatore, A.J., Straw, M.L., \& Ford, M.L., 1997. Pearl millet in layer diets enhances egg yolk n-3 fatty acids. Poult. Sci. 76, 326-330.

Costa, F.G.P., Souza, C.J., Goulart, C.C., Lima Neto, R.C., Costa, J.S., Pereira, W.E., 2008. Performance, and quality of eggs of semidried hens fed diets containing soybean and canola oils. Bras. Zootec. 37, 1412-1418.

de Morais Oliveira, V.R., de Arruda, A.M.V., Silva, L.N.S., de Souza, J.B.F., de Queiroz, J.P.A.F., da Silva Melo, A., Holanda, J.S., 2016. Sunflower meal as a nutritional and economically viable substitute for soybean meal in diets for free-range laying hens. Anim. Feed Sci. Technol. 220,103-108.

Foidl, N., Makkar, H.P.S, \& Becker, K., 2001. The Potential of Moringa oleifera for agricultural and industrial use. Proceedings of the 11th Workshop. "What development potential for Moringa products", DaresSalaam, Tanzania. pp. 47-67

Garaffo, M. A., Vassallo-Agius, R., Nengas, Y. L., Elvira, Rando, R., Maisano, R., Dugo, G. \& Giuffrida. D., 2011. Fatty Acids Profile, Atherogenic (IA) and Thrombogenic (IT) Health Lipid Indices, of Raw Roe of Blue Fin Tuna (Thunnus thynnus L.) and their salted product "Bottarga". Food Nutr Sci. 2, 736-743.

Garces, R., \& Mancha, M., 1993. One-step lipid extraction and fatty acid methyl esters preparation from fresh plant tissues. Anal. Biochem. 1, 139-143.

Hammershøj, M., Steenfeldt, S., 2005. Effects of blue lupin (Lupinus angustifolius) in organic layer diets and supplementation with foraging material on egg production and some egg quality parameters. Poult. Sci. 84, 723-733.

Hassan, K.U., Khalique, A., Pasha, T.N., Akram, M., Mahmood, S., Sahota, A.W., Imran, M.S. \& Saleem, G., 2017. Influence of Moringa oleifera decorticated seed meal on broiler performance and immunity. Pak Vet J. 37, 47-50.

Laudadio, V., E. Ceci., \& V. Tufarelli., 2011. Productive traits and meat fatty acid profile of broiler chickens fed diets containing micronized fava beans (Vicia faba L. var. minor) as the main protein source. J. Appl. Poult. Res. 20,12-20.

Mabruk, A.A., Talib, H.N., Mohamed, M.A., \& Alawad, A.H., 2010. A note on the potential use of moringa oleifera tree as animal feed, Hillat Kuku. J. Vet. Med. Anim. Prod. 2, 184-188.

Monira, K. N., Salahuddin, M., \& Miah, G., 2003. Effect of breed and holding period on egg quality characteristics of chicken. Int. J. Poult. Sci. 4, 261-263.

Moreki, J. C., \& Gabanakgosi, K., 2014. Potential use of moringa oleifera in poultry diets. Global J. Anim. Sci. Ses. 2, 109- 115.

National Research Council., 1994. Nutrient Requirements for Poultry. 9th rev. ed. National Academy Press, Washington, DC.

Nkukwana, T.T., Muchenje, V., Pieterse, E., Masika, P.J., Mabusela, T.P., Hoffman, L.C. \& Dzama, K. 2014. Effect of Moringa oleifera leaf meal of growth performance, apparent digestibility, digestive organ size and carcass yield in broiler chickens. Livest Sci. 116, 139-146.

Novak, C., \& S. E. Scheideler., 2001. Long-term effects of feeding flaxseed-based diets. 1. Egg production parameters, components, and eggshell quality in two strains of laying hens. Poult. Sci. 80, 1480-1489.

Paguia, H.M., Paguia, R.Q., Balba, C. \& Flores, R.C., 2014. Utilization and evaluation of Moringa oleifera L. as poultry feeds. 4th International Conference on Agriculture and Animal Science. 8, 343-7. 
Parmer, S.N.S., Thakur, M.S., Tomar, S.S., \& Pillar, P.V.A., 2006. Evaluation of egg quality traits in indigenous Kadaknath breed of poultry. Livestock Res Rural Dev.9. http:// www.Irrd.org//rrd18/9/parm18132htm.

SAS Institute., 2004. SAS User's Guide: Statistics, version 9.1 ed SAS Institute., Cary, New City 〈www.sas.com〉.

Sayda, A., Ali, M., Hyder, O., Abdalla \& Abasaid, M.A., 2011. Sunflower meal as an alternative protein source to groundnut meal in laying hens ration. Egypt. Poult. Sci. 31, 745-753.

Senso, L., Suárez, M.D., Ruiz-Cara, T., \& García-Gallego, M., 2007. On the Possible effects of harvesting season and chilled storage on the fatty acid profile of the filled of farmed gilthead sea bream (Sparus aurata). Food Chem. 101, 298-307.

Shi, S. R., Lu, J., Tong, H. B., Zou, J. M., \& Wang, K. H., 2012. Effects of graded replacement of soybean meal by sunflower seed meal in laying hen diets on hen performance, egg quality, egg fatty acid composition and cholesterol content. J Appl Poult Res. 21, 367-374.

Soetan, K.O., \& Oyewole, O.E., 2009. The need for adequate processing to reduce the anti-nutritional factors in plants used as human foods and animal feeds: A review. Afr. J. Food Sci. 3, 223-232.

Stadelman, W. J., 2002. Quality identification of shell eggs. In: Egg Science and Technology. (Eds: William J. Stadelman and Owen J. Cotterill). 4th ed. CBS Publishers \& Distributors. New Delhi. pp. 39-64.

Talha, E.A., \& Ahmed, M.E., 2012. Use of Moringa oleifera seeds in broiler diets and its effects on the performance and carcass characteristics. J Appl Poult Res. 1, 1-4.

Tesfaye, E.B., Animut, G.M., Urge, M.L. \& Dessie, T.A., 2014. Cassava root chips and Moringa oleifera leaf meal as alternative feed ingredients in the layer ration. J. Appl. Poult. Res. 23, 614-624.

Tsiplakou, E., Zervas, G., 2008. The effect of dietary inclusion of olive tree leaves and grape marc on the content of conjugated linoleic acid and vaccenic acid in the milk of dairy sheep and goats. J. Dairy Res. 3, 270-278.

Tsuzuki, É.T., Garcia, E.R., De, M., Murakami, A.E., Sakamoto, M.I., \& Galli, J.R., 2003. Utilization of sunflower seed in laying hen rations. Braz J Poult Sci. 3, 179-182.

van Soest, P.J., Robertson, J.B., \& Lewis, B.A., 1991. Methods for dietary fiber, neutral detergent fiber and non-starch polysaccharides in relation to animal nutrition. J Dairy Res. 74, 3583-3597.

Wapi, C., Nkukwana, T.T., Hoffman, L.C., Dzama, K., Pieterse, E., Mabusela, T. \& Muchenje, V., 2013. Physico-chemical shelf-life indicators of meat from broilers given Moringa oleifera leaf meal. S. Afr. J. Anim. Sci. 43 (Supp. 1), 43-47. 